EESTI NSV TEADUSTE AKADEEMIA TOIMETISED, 27. KÖDE

KEEMIA. 1978, NR. 3

ИЗВЕСТИЯ АКАДЕМИИ НАУК ЭСТОНСКОИ ССР. ТОМ 27 ХИМИЯ. 1978, № 3

М. КРУЛЛЬ, АйлИ КОГЕРМАН, О. КИРРЕТ,

удК 677.499.543.544 Елена ПЛЫГАНЬ, А. ЮДНН, Аза ШЕВЧЕНКО

\title{
ПИРОЛИТИЧЕСКАЯ ГАЗОВАЯ ХРОМАТОГРАФИЯ ПОЛИФОРМАЛЬДЕГИДНЫХ ВОЛОКОН
}

Для характеристики поведения полимеров и полимерных систем при повышенных температурах все чаще, наряду с обычными методами определения термической стабильности, применяются газохроматографические, позволяющие определить не только суммарный выход летучих продуктов деструкции, но и их химический состав.

Доступность исходного сырья и высокие механические свойства полиформальдегида определяют целесообразность его применения и, в первую очередь, термостабильных сополимеров формальдегида с диоксоланом для производства синтетических волокон [']. Термостабильность указанных волокон может быть увеличена путем добавления стабилизаторов.

Мы пользовались методикой пиролитической газовой хроматографии (ПГХ), которая позволила нам охарактеризовать состав и количество продуктов термической деструкции полимера при кратковременных перегревах материала $\left[{ }^{2}\right]$.

ПГХ (аппаратура, конструкция реактора-пиролизатора и схема анализа продуктов пиролиза) применялась ранее при изучении влияния термостабилизаторов типа эфиров 4-оксидифениламина на количественный состав продуктов термодеструкции поликапроамида $\left[{ }^{3}\right]$.

Таблица 1

Состав волокон из сополимеров триоксана и формальдегида с диоксоланом

\begin{tabular}{l|c|c|c|c|c|c}
\hline \multirow{3}{*}{ Волокно } & \multicolumn{6}{|c}{ Стабилизатор, \% } \\
\cline { 2 - 6 } & С-475 & C-471 & Д山ДА & НГ & СТ-3 & $\begin{array}{c}\text { пинувин } \\
327\end{array}$ \\
\hline
\end{tabular}

СТД-1

СТД-2

СТД-3

СТД-4

СТД-5

СТД-6

СФД-1

СФД-2

СФД-3

СФД-4

СФД-5

СФД-6

$\begin{array}{lll}\overline{-} & \overline{\overline{ }} & \overline{0,5} \\ \overline{\overline{0}} & \overline{0,5} & 0,5 \\ \overline{\overline{1}} & \overline{\overline{5}} & 0,5 \\ \overline{0} & \overline{-} & \overline{-} \\ \overline{-} & \overline{-} & 0,5 \\ \overline{-} & \overline{-} & \overline{0} \\ \overline{-} & \overline{-} & 0,5 \\ - & - & 0,5\end{array}$

$\begin{array}{lll}\overline{0,5} & \overline{-} & - \\ 0,5 & - & - \\ 0,5 & - & - \\ \overline{-} & \overline{-} & \overline{-} \\ \overline{\overline{0}} & \overline{-} & \overline{-} \\ \overline{0} & \overline{-} & \overline{-} \\ 0,5 & \overline{1,5} & \overline{-} \\ 0,5 & 0,5 & -\end{array}$



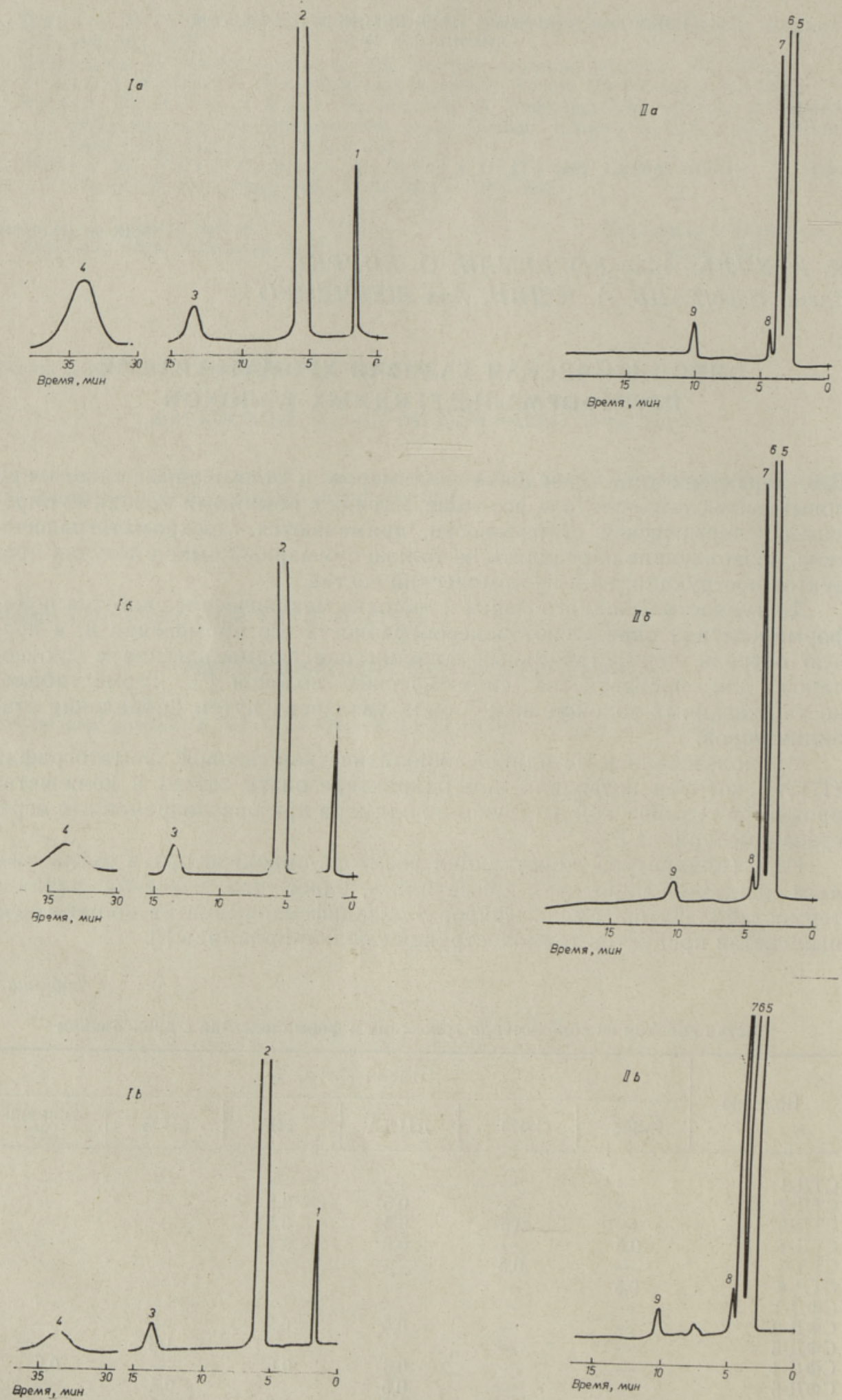

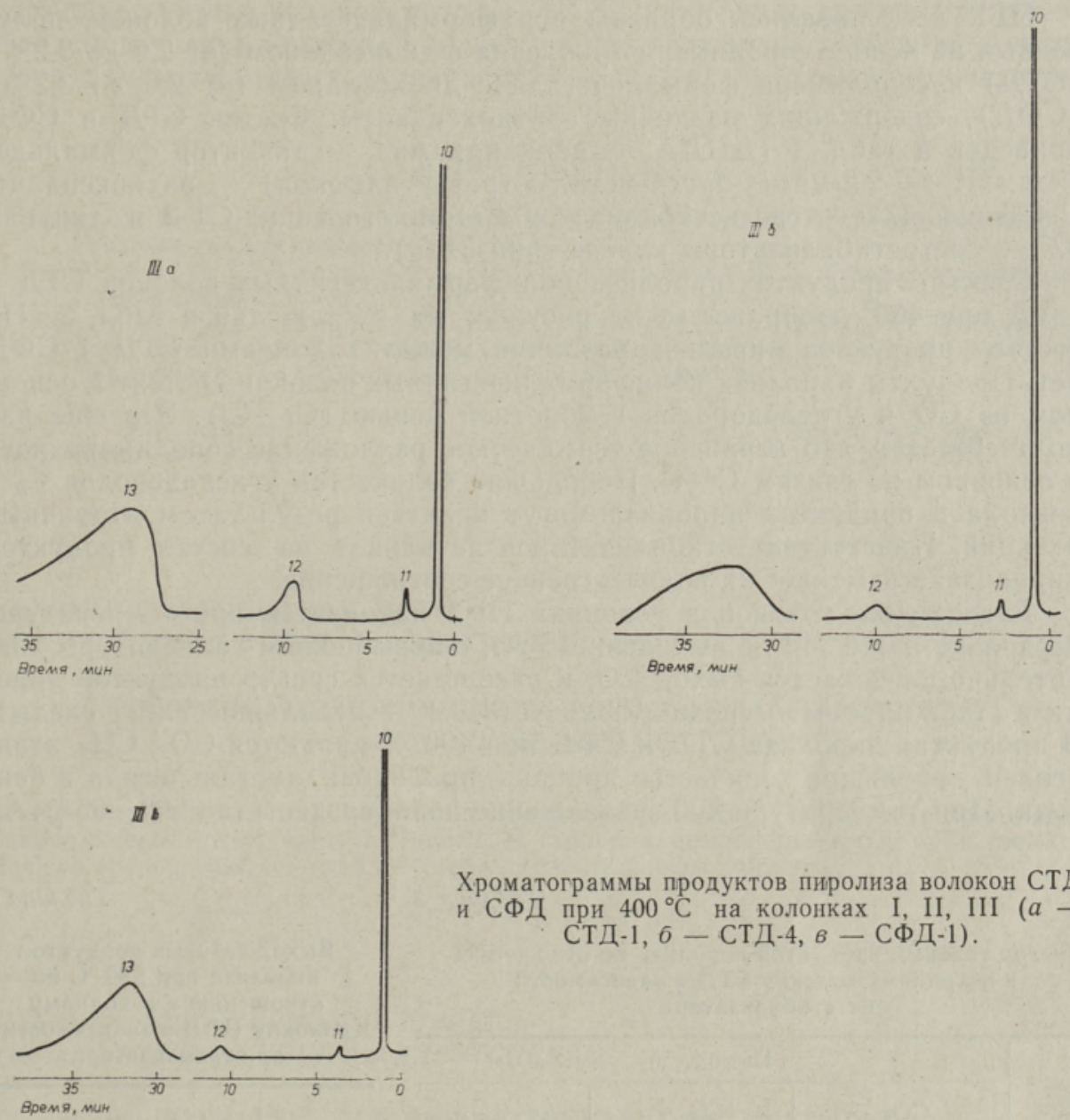

Хроматограммы продуктов пиролиза волокон СТД и СФД при $400^{\circ} \mathrm{C}$ на колонках I, II, III ( $a-$ СТД-1, 6 - СТД- $4,8-$ СФД-1).

Таблица 2

Состав продуктов пиролиза волокон СТД и СФД

\begin{tabular}{|c|c|c|c|c|c|}
\hline \multirow{2}{*}{ 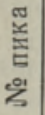 } & \multirow{2}{*}{$\begin{array}{c}\text { Продукты } \\
\text { пиролиза }\end{array}$} & \multicolumn{3}{|c|}{ Волокно } & \multirow{2}{*}{ Условия пиролиза } \\
\hline & & СТД-1 & СТД-4 & СФД-1 & \\
\hline
\end{tabular}

\begin{tabular}{|c|c|c|c|c|c|}
\hline & $\begin{array}{l}\mathrm{H}_{2} \\
\mathrm{CO} \\
\mathrm{CH}_{4} \\
\mathrm{CO}_{2}\end{array}$ & $\begin{array}{r}+ \\
+ \\
+ \\
+\end{array}$ & $\begin{array}{r}+ \\
+ \\
+ \\
+\end{array}$ & $\begin{array}{r}+ \\
+ \\
+ \\
+ \\
+\end{array}$ & $\begin{array}{l}\text { Колонка I: длина } 3 \text {, диам. } 3,5 \text { мм, } \\
\text { с активированным углем, } 46^{\circ} \mathrm{C} \text {, ско- } \\
\text { рость газа-носителя Не } 4,5 \text { л/час, } \\
\text { давл. } 0,78 \text { ат }\end{array}$ \\
\hline $\begin{array}{l}5 \\
6 \\
7 \\
8 \\
9\end{array}$ & $\begin{array}{l}\mathrm{C}_{2} \mathrm{H}_{6} \\
\text { Этилен } \\
\text { Пропан } \\
\text { Пропилен } \\
\text { цис-2-Бутан }\end{array}$ & $\begin{array}{l}++ \\
++ \\
+ \\
\text { сл. } \\
\text { сл. }\end{array}$ & $\begin{array}{r}++ \\
++ \\
+ \\
\text { cл. } \\
\text { сл. }\end{array}$ & $\begin{array}{l}++ \\
++ \\
+ \\
\text { cл. } \\
\text { сл. }\end{array}$ & $\begin{array}{l}\text { Колонка II: длина } 6 \text { м, диам. } 3,5 \text { м.м, } \\
\text { хромосорб Р } 60-80 \text { меш. с } 2,4 \text {-диме- } \\
\text { тилсульфоланом в соотношении } \\
80: 20,25{ }^{\circ} \mathrm{C} \text {, скорость газа-носителя } \\
3,8 л / 4 a c, \text { давл. } 1,35 \text { ат }\end{array}$ \\
\hline $\begin{array}{l}10 \\
11 \\
12\end{array}$ & $\begin{array}{l}\text { Ацетальдегид } \\
\text { Бензол } \\
\text { Нендентифи- } \\
\text { цированные }\end{array}$ & $\begin{array}{r}\text { сл. } \\
+ \\
++\end{array}$ & $\begin{array}{r}\text { сл. } \\
+ \\
++\end{array}$ & $\begin{array}{r}\text { сл. } \\
+ \\
++\end{array}$ & $\begin{array}{l}\text { Колонка III: длина } 3,5 \text { м, диам. } 3 \text { мм, } \\
\text { хромосорб Р } 60-80 \text { меш. с полиэти- } \\
\text { ленгликолем } 1500 \text { в соотношении } \\
80: 20,100{ }^{\circ} \mathrm{C} \text {, скорость газа-носителя } \\
3,8 \text { л/час, давл. } 2,3 \text { ат }\end{array}$ \\
\hline
\end{tabular}


ПГХ исследовались образцы полиформальдегидных волокон, полученных на основе сополимера триоксана с диоксоланом (от 2,6 до 3,2\%) (СТД) и сополимера формальдегида с диоксоланом (от 2,6 до 3,2\%) (СФД), содержащих различные антиоксиданты. Состав СТД и СФД приведен в табл. 1 (ДЦДА - дициандиамид - акцептор формальдегида; НГ - 2,2-метил-бис (4-метил-6-третбутилфенол) - антиоксидант; C-475 -и C-471 - светостабилизаторы аминного типа; СТ-3 и тинувин 327 - светостабилизаторы класса триазолов).

Спектры продуктов пиролиза полиформальдегидных волокон СТД и СФД при $400^{\circ}$ изображены на рисунке, их состав дан в табл. 2. По составу продуктов пиролиза различий между волокнами СТД и СФД нет. Продукты пиролиза полиформальдегидных волокон состоят в основном из СО и углеводородов с короткой цепью $\left(\mathrm{C}_{1}-\mathrm{C}_{2}\right)$. Это еще раз подтверждает, что первичное термическое разложение сополимера идет в основном по связям С-O. Небольшие количества углеводородов $\mathrm{C}_{3}$ и бензола в продуктах пиролиза могут являться результатом вторичных реакций. Присутствие стабилизаторов не влияет на состав продуктов пиролиза, а изменяет их количественное соотношение.

Разложение волокон в условиях ПГХ начинается при температуре, несколько ниже $250^{\circ}$, с выделением СО; с повышением температуры значительно повышается выход СО, и расширяется спектр продуктов пиролиза (табл. $2 ;++-$ среднее количество, +- небольшое, сл. - следы). В продуктах пиролиза СТД и СФД при $400^{\circ}$ появляются $\mathrm{CO}_{2}, \mathrm{CH}_{4}$, этан, этилен, небольшое количество пропана, пропилена, ацетальдегида и бензола. При температуре $400^{\circ}$ разложение волокна достигает $90-95 \%$.

таблица 3

Таблица 4

Выход газовых продуктов пиролиза по отношению к исходному волокну СТД в зависимости от стабилизатора

\begin{tabular}{|c|c|c|c|c|c|c|}
\hline \multirow{3}{*}{ 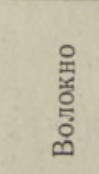 } & \multicolumn{6}{|c|}{ Выход, \% } \\
\hline & \multicolumn{2}{|c|}{$\mathrm{CO}$} & \multicolumn{2}{|c|}{$\mathrm{CO}_{2}$} & \multicolumn{2}{|c|}{$\mathrm{CH}_{4}$} \\
\hline & $300^{\circ}$ & $350^{\circ}$ & $300^{\circ}$ & $350^{\circ}$ & $300^{\circ}$ & $350^{\circ}$ \\
\hline $\begin{array}{l}\text { СТД-1 } \\
\text { СТД-2 } \\
\text { СТД-3 } \\
\text { СТД-4 } \\
\text { СТД-5 } \\
\text { СТД- } 6\end{array}$ & $\begin{array}{r}100 \\
67,5 \\
90,0 \\
62,5 \\
40,0 \\
42,5\end{array}$ & $\begin{array}{r}100 \\
96,0 \\
109,0 \\
97,5 \\
86,5 \\
103,0\end{array}$ & $\begin{array}{l}0 \\
0 \\
0 \\
0 \\
0 \\
0\end{array}$ & $\begin{array}{c}100 \\
47,5 \\
71,3 \\
42,8 \\
57,0 \\
90,4\end{array}$ & $\begin{array}{l}0 \\
0 \\
0 \\
0 \\
0 \\
0\end{array}$ & $\begin{array}{l}100 \\
100 \\
100 \\
100 \\
100 \\
100\end{array}$ \\
\hline
\end{tabular}

\begin{tabular}{|c|c|c|c|}
\hline \multicolumn{4}{|c|}{$\begin{array}{c}\text { Выход газовых продуктов } \\
\text { пиролиза при } 350^{\circ} \mathrm{C} \text { по } \\
\text { отношению к исходному } \\
\text { волокну СФД в зависимости } \\
\text { от стабилизатора }\end{array}$} \\
\hline \multirow{2}{*}{$\begin{array}{c}\text { Волок- } \\
\text { но }\end{array}$} & \multicolumn{3}{|c|}{ Выход, \% } \\
\hline & $\mathrm{CO}$ & $\mathrm{CO}_{2}$ & $\mathrm{CH}_{4}$ \\
\hline $\begin{array}{l}\text { СФД-1 } \\
\text { СФД-2 } \\
\text { С } Ф Д-3 \\
\text { СФД-4 } \\
\text { СФД-5 } \\
\text { СФД-6 }\end{array}$ & $\begin{array}{r}100 \\
29 \\
85 \\
42 \\
72 \\
39\end{array}$ & $\begin{array}{c}100 \\
0 \\
89 \\
94,5 \\
67 \\
100\end{array}$ & $\begin{array}{r}100 \\
50 \\
50 \\
50 \\
50 \\
0\end{array}$ \\
\hline
\end{tabular}

В табл. 3 и 4 приведены данные о выходах газовых продуктов пиролиза в зависимости от состава стабилизаторов по отношению к исходным СТД и СФД. Приведенные данные показывают, что все исследуемые стабилизаторы в области температур пиролиза $300-350^{\circ}$ сильно ингибируют выделение $\mathrm{CO}$ и $\mathrm{CO}_{2}$. Этот факт служит подтверждением предположения о том, что применяемые в наших исследованиях органические соединения, содержащие аминогруппы и являющиеся в принципе типичными светостабилизаторами для полимеров (С-475, С-471, СТ-3, тинувин 327), одновременно являются и достаточно эффективными термостабилизаторами для полиформальдегидных волокон.

Результаты исследования состава летучих продуктов пиролиза поли- 
формальдегидных волокон методом ПГХ аналогичны данным, полученным при изучении термостабильности названных волокон по потери прочности при повышенных температурах и при исследовании их методом ТГА.

\section{Л ИТ Е Р А Т Р А}

1. Егоров Б. А., Гр жималовски й А. С., Юдин А. В. Полиформальдегидные волокна. - Хим. волокна, 1969, № 4, с. 35.

2. Березкин В. Г., Алишоев В. Р., Нем ер овская И. Б. Газовая хроматография в химии полимеров. М., 1972.

3. Krul1, M., Kogerma n, A., Kirret, O., Kuty in a, L., Z a polski, D. Pyrolysis gas chromatography of capron (nylon-6) fibre stabilized with ethers of 4-oxydiphenylamine. - J. Chromatogr., 1977, v. 135, p. 2112-2116.

Институт химии
Академии наук Эстонской ССР

M. KRULL, Aili KOGERMAN, O. KIRRET,

Jelena PLOGAN, A. JUDIN, Aza SEVTSENKO
Поступила в редакцию $24 /$ II 1978

\section{POLUFORMALDEHUODKIUDUDE POROLUUS-GAASIKROMATO- GRAAFILINE ANALOUS}

Artiklis on käsitletud stabiliseeritud polüformaldehüüdkiudude lenduvate pürolüüsiproduktide kvantitatiivset koostist. Ilmneb, et mōned valgusstabilisaatorid, mille molekul sisaldab aminogruppe, toimivad ka efektiivsete termostabilisaatoritena.

M. KRULL, Aili KOGERMAN, O. KIRRET, Yelena PLYGAN, A. YUDIN, Asa SHEVTCHENKO

\section{PYROLYSIS GAS CHROMATOGRAPHY OF POLYFORM- ALDEHYDE FIBRES}

The quantitative dependence of the yields of light pyrolysis products of polyformaldehyde fibres on the structure of the stabilizer has been studied.

According to data on pyrolysis gas chromatography, the stabilizers containing amino groups in the molecule act as both light stabilizers and thermostabilizers. 